\title{
Esterification of reduced glutathione
}

\author{
Paul K. THORNALLEY \\ Department of Chemistry and Biological Chemistry, University of Essex, Wivenhoe Park, Colchester CO4 3SQ, U.K.
}

\begin{abstract}
GSH monoethyl ester [ $\gamma$-L-glutamyl-L-cysteinyl(ethyl glycinate)] may be used to supplement cellular pools of GSH in vitro and in vivo. The compound was prepared by esterification of GSH in anhydrous ethanol with $\mathrm{HCl}$ as the catalyst. However, a full analysis of products from the esterification of GSH revealed the formation of minor products: $\gamma$-L-(ethyl glutamyl)-L-cysteinylglycine, i.e. an isomeric monoester, $\gamma$-L-(ethyl glutamyl)-L-cysteinyl(ethyl glycinate), i.e. GSH diethyl ester, and $N$-(3-amino-2,6-dioxopiperazino)-L-cysteinyl(ethyl glycinate), i.e. an acid-catalysed cyclization product. These compounds were separated and purified by reverse-phase h.p.l.c. Esterification of GSH produces mainly the glycyl monoester with minor products of $\gamma$-glutamyl ester, diester and the cyclization product. Only analytical reverse-phase h.p.l.c. of the compounds was found to resolve these products.
\end{abstract}

\section{INTRODUCTION}

GSH monoethyl ester [ $\gamma$-L-glutamyl-L-cysteinyl(ethyl glycinate)] was introduced by Puri \& Meister (1983) as a prospective experimental agent to supplement cellular pools of GSH. After intraperitoneal injection in rats, it was distributed around the body and penetrated many tissues. It was found to be resistant to cleavage by $\gamma$-glutamyltranspeptidase and it was hydrolysed to GSH by a cytosolic non-specific esterase (Wellner et al., 1984; Anderson et al., 1985). The cellular concentration of GSH cannot be generally supplemented by administration of exogenous GSH or amino acid and peptide substrates for GSH synthesis because of feedback inhibition of $\gamma$-glutamyl synthetase (Richman \& Meister, 1983). Administration of GSH monoester circumvents this by delivering GSH directly and intact into the cell cytosol.

It now seems possible that GSH monoethyl ester (and monoisopropyl ester) may be future pharmaceutical agents for the alleviation of toxicity associated with ionizing radiation (Wellner et al., 1984; Astor et al., 1988; Vos \& Roos-Verhey, 1988), cytotoxic antitumour agents (Teicher et al., 1988), paracetamol overdose and similar hepatotoxicity (Uhlig \& Wendel, 1990), and disease processes such as ischaemia and anaemia (Bottje et al., 1989; Noguchi et al., 1989). However, some reports suggest that GSH esters are toxic, which may limit the dose and therapeutic use of these compounds (Vos \& Roos-Verhey, 1988; Tsan et al., 1989). This toxicity is thought to be related to contaminating GSH diethyl ester.

GSH esters are prepared by acid-catalysed esterification, producing acid salts of GSH monoester and GSH diester. In GSH monoester the esterified group was thought to be exclusively on the glycine residue (Anderson et al., 1985). There is now an urgent demand for procedures to purify esters of GSH to a high grade of purity, salt-free, suitable for biological evaluation.

In the present paper I describe the synthesis of esters of GSH by acid-catalysed esterification and purification by preparative reverse-phase h.p.l.c. This has revealed the formation of two isomeric monoesters, the diester and an acid-catalysed cyclization product. However, for short $(30 \mathrm{~min})$ esterification periods the GSH monoester $\gamma$-L-glutamyl-L-cysteinyl(ethyl glycinate) is the major product. Preparative reverse-phase h.p.l.c. may be used to produce high-purity preparations of all of these products for biological evaluation.

\section{MATERIALS AND METHODS}

\section{GSH}

GSH was purchased from Sigma Chemical Co. (Poole, Dorset, U.K.).

\section{Esterification}

Ethanol $(5 \mathrm{ml})$ was put in a small glass screw-capped vial, and $\mathrm{HCl}$ gas $(0.305 \mathrm{~g})$ was bubbled into it, as measured by increase in sample weight. GSH $(0.5 \mathrm{~g})$ was dissolved in the ethanolic $\mathrm{HCl}$ solution and incubated at $25^{\circ} \mathrm{C}$ for $30 \mathrm{~min}$.

\section{Sample preparation for chromatography}

After incubation, the reaction mixture was freeze-dried in a centrifugal evaporator. The residue was reconstituted with $1 \mathrm{ml}$ of mobile phase for h.p.l.c., namely $13.8 \mathrm{~mm}$-formic acid, $\mathrm{pH} 2.83$. The $\mathrm{pH}$ of the sample was restored to 2.83 by addition of aqueous $\mathrm{NH}_{3}$ solution (sp.gr. 0.880).

\section{Preparative reverse-phase h.p.l.c.}

GSH esters were purified by using a reverse-phase ODS $(6.0 \mathrm{~nm}$ pore size; $6 \mu \mathrm{m}$ particle size $)$ cartridge $(25 \mathrm{~mm} \times 10 \mathrm{~cm})$ with a $1 \mathrm{~cm}$ guard cartridge in a radial compression module (Waters-Millipore, Watford, Herts., U.K.). The mobile phase was $13.8 \mathrm{~mm}$-formic acid, $\mathrm{pH} 2.83$, with a flow rate of $10 \mathrm{ml} / \mathrm{min}$ and a linear gradient of $0-80 \%(\mathrm{v} / \mathrm{v})$ methanol from 10 to $30 \mathrm{~min}$ after sample injection. The sample was approx. $125 \mathrm{mg}$ of esterification product. The eluate was monitored at $230 \mathrm{~nm}$. Fractions corresponding to peak absorbances were collected and freeze-dried. The freeze-dried material was reconstituted in initial mobile phase and the chromatography was repeated.

\section{Analytical reverse-phase h.p.l.c.}

The purity of purified GSH esterification products was assessed by analytical reverse-phase h.p.l.c. with an ODS $(6.0 \mathrm{~nm}$ pore size; $4 \mu \mathrm{m}$ particle size) cartridge $(8 \mathrm{~mm} \times 10 \mathrm{~cm})$ in a radial compression module (Waters). GSH derivative $(1 \mathrm{mg})$ was dissolved in $1 \mathrm{ml}$ of mobile phase, namely $10 \mathrm{mM}-\mathrm{H}_{3} \mathrm{PO}_{4} / \mathrm{NaH}_{2} \mathrm{PO}_{4}$, pH 2.83 , containing $0.25 \mathrm{mg}$ of $S$-methylglutathione $/ \mathrm{ml}$ as the internal standard. A $50 \mu$ l sample was analysed. The mobile phase was $10 \mathrm{~mm}-\mathrm{H}_{3} \mathrm{PO}_{4} / \mathrm{NaH}_{2} \mathrm{PO}_{4}, \mathrm{pH} 2.83$, with a linear gradient of $0-50 \%(\mathrm{v} / \mathrm{v})$ methanol over $20 \mathrm{~min}$. The flow rate was $2 \mathrm{ml} / \mathrm{min}$. The eluate was monitored at $220 \mathrm{~nm}$.

\section{Characterization of products}

The purified products were analysed by proton n.m.r. on a $270 \mathrm{MHz}$ Fourier-transform n.m.r. spectrometer. Products were also analysed by t.l.c. on silica gel $60 \mathrm{~F}_{234}$ plates (BDH Chemicals, Poole, Dorset, U.K.) in three solvent systems. 

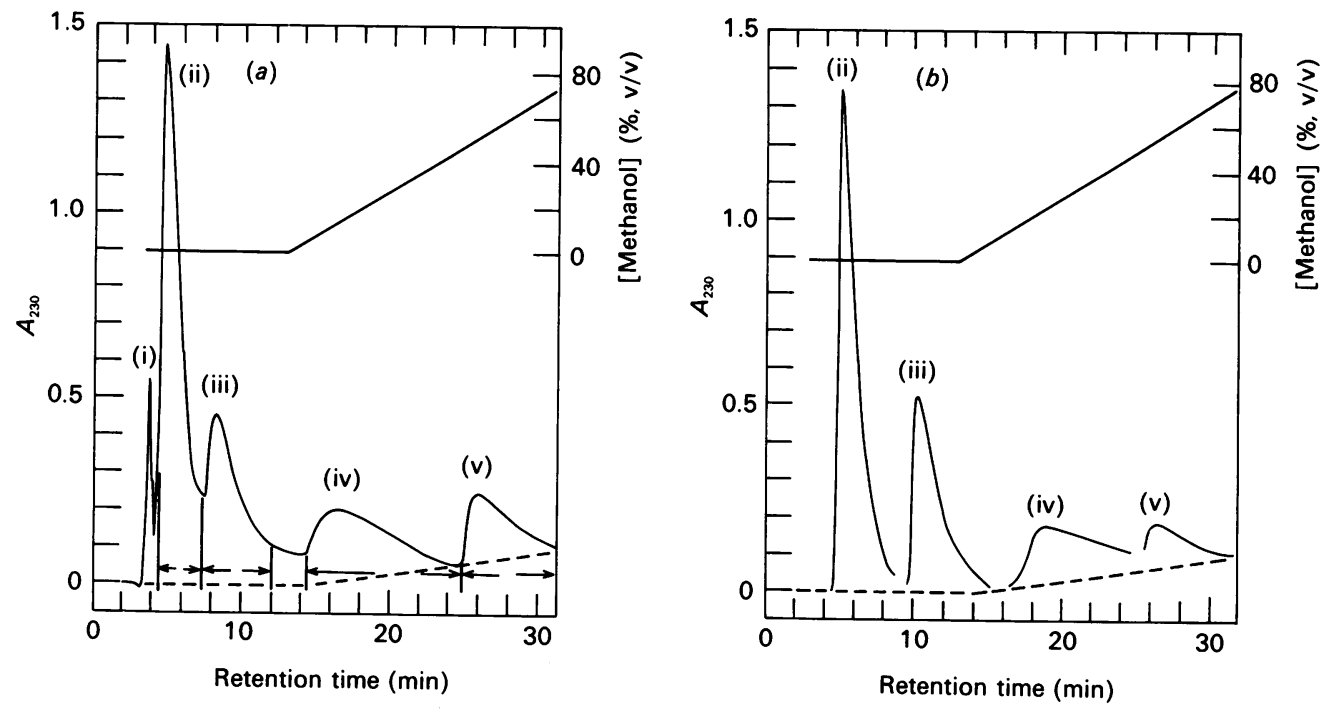

Fig. 1. Preparative reverse-phase h.p.l.c. of GSH esterification products

(a) Sample: $125 \mathrm{mg}$ of a 30 min esterification product mixture in mobile phase $(0.5 \mathrm{ml}), \mathrm{pH} 2.83$. (b) Overlay of chromatograms of pure fractions (ii), (iii), (iv) and (v), produced by repeated reverse-phase chromatography. Fraction assignments (see the text): (i) GSH and formate; (ii) GSHEt $_{\text {Gly }}$; (iii) GSHEt $\mathrm{Glu}_{\text {il }}$; (iv) $\mathrm{GSHEt}_{2}$; (v) $\mathrm{GSH}_{\text {cycl }}$. The ODS column size was $25 \mathrm{~mm}$ internal diam. $\times 10 \mathrm{~cm}$, the flow rate was $10 \mathrm{ml} / \mathrm{min}$, the mobile phase was $13.8 \mathrm{~mm}$-formic acid, $\mathrm{pH} 2.83$, and the gradient was $0-80 \%(\mathrm{v} / \mathrm{v})$ methanol during $10-30 \mathrm{~min}$.

\section{RESULTS}

\section{Purification of GSH esters}

When GSH was incubated in ethanolic $\mathrm{HCl}$ for $30 \mathrm{~min}$ at $25^{\circ} \mathrm{C}$, preparative reverse-phase h.p.l.c. of the crude product mixture partially resolved four major fractions, which were further purified by fractionation and repeat chromatography (Figs. $1 a$ and $1 b$ ). The compounds in the fractions were identified by proton n.m.r. (Rabenstein \& Keire, 1989) (Table 1).

Fraction (i) contained formate ions and residual GSH. Fraction (ii) comprised the major fraction and was identified as the monoethyl ester of GSH from the proton-n.m.r. spectrum (Table 1); $\delta\left(\mathrm{CH}_{2}\right)_{\mathrm{ethyl}}=4.01$ p.p.m. and $\delta\left(\mathrm{CH}_{3}\right)_{\text {ethyl }}=1.13$ p.p.m. Fraction (iii) was eluted shortly after fraction (ii), and the protonn.m.r. spectrum suggested this was also a monoethyl ester of GSH. However, inspection of the resonances for the $\alpha-\mathrm{CH}$ of the the glutamic acid residue and the $\alpha-\mathrm{CH}_{2}$ of the glycine residue reveal distinctive characteristics. The compound from fraction (ii) gave an $\alpha-\mathrm{CH}$ (glutamic acid) resonance at 3.65 p.p.m.; cf. $\delta=3.91$ p.p.m. for fraction (iii) and $\delta=3.78$ p.p.m. for GSH (deprotonation of the carboxylic acid group of the glutamic acid residue decreases the chemical shift of the $\alpha-\mathrm{CH}$ resonance). The resonance for the $\alpha-\mathrm{CH}_{2}$ of the glycine residue for fraction (ii) reflected magnetic inequivalence of the two $\alpha$-protons, consistent with restricted rotation around the glycine $\mathrm{CH}_{2}$ group. Neither fraction (iii) nor GSH gave this methylene proton inequivalence. These characteristics suggest that fraction (ii) contains GSH esterified on glycine, i.e. $\gamma$-L-glutamyl-L-cysteinyl(ethyl glycinate) $\left(\mathrm{GSHEt}_{\mathrm{Gly}}\right)$, and fraction (iii) contains GSH esterified on the glutamic acid residue, i.e. $\gamma$-L-(ethyl glutamyl)-L-cysteinylglycine $\left(\mathrm{GSHEt}_{\mathrm{Glu}}\right)$.

Fraction (iv) gave a proton-n.m.r. spectrum of GSH esterified with two ethyl groups. The chemical shifts and hyperfine structure of the resonances of the $\alpha-\mathrm{CH}$ of the glutamic acid residue and the $\alpha-\mathrm{CH}_{2}$ of the glycine residue are consistent with esterification, as observed for GSHEt $_{\text {Glu }}$ and GSHEt $_{\text {Gly }}$ respectively. This compound was therefore the diethyl ester of GSH, i.e. $\gamma$-L-(ethyl glutamyl)-L-cysteinyl(ethyl glycinate) $\left(\mathrm{GSHEt}_{2}\right)$.

Fraction (v) contained a compound that analysis by proton n.m.r. spectroscopy suggested to be a diester from the chemical- shift changes of the $\alpha-\mathrm{CH}$ of the $\gamma$-glutamic acid residue and the $\alpha-\mathrm{CH}$ of the glycine residue. However, there was only one ethyl group present and increased magnetic inequivalence and complexity of the resonances for the $\beta$ - and $\gamma$-protons of the glutamic acid residue. This is consistent with the cyclized derivative of GSH ester, i.e. $N$-(3-amino-2,6-dioxopiperazino)-L-cysteinyl(ethyl glycinate) (GSHEt $\left.{ }_{\text {cycl }}\right)$.

Analytical reverse-phase h.p.l.c. of these GSH derivatives resolved all these compounds (Fig. 2). T.l.c. on silica gel, in contrast, did not resolve the two forms of monoester or the diester and cyclization product (Table 2). These t.l.c. conditions have been previously used to determine the purity of GSH esterification products (Anderson et al., 1985).

The yields of the GSH esterification products from $500 \mathrm{mg}$ of GSH were GSHEt $\mathrm{Gly}_{\mathrm{Gl}}$, approx. $200 \mathrm{mg}(40 \%), \mathrm{GSHEt}_{\mathrm{Glu}}$, approx. $50 \mathrm{mg}(10 \%), \mathrm{GSHEt}_{2}$, approx. $30 \mathrm{mg}(6 \%)$, and $\mathrm{GSH}_{\mathrm{cycl}}$, $20 \mathrm{mg}(4 \%)$. The overall recovery was $60 \%$, which reflects loss during fractionation and oxidation during manipulation.

\section{DISCUSSION}

It is now widely accepted that the monoester of GSH is the most effective, generally applicable and preferred derivative of GSH for supplementation of cellular concentrations of GSH (Meister, 1988). Addition of exogenous GSH may lead to significant increases in cellular GSH concentrations in some tissues by extracellular degradation and intracellular synthesis de novo (Anderson et al., 1985; Singh et al., 1989; Tsan et al., 1989), or in intestinal epithelium, alveolar type II epithelial cells and kidney cells by active transport (Lash \& Jones, 1984; Hagen et al., 1986; Lash et al., 1986). However, monoesterification of GSH improves cellular penetration, confers resistance to extracellular degradation by $\gamma$-glutamyltranspeptidase and is generally applicable, increasing cellular concentrations of GSH in most cells in vitro and in vivo (Wellner et al., 1984; Anderson et al., 1985; Astor et al., 1988; Vos \& Roos-Verhey, 1988; Teicher et al., 1988; Bottje et al., 1989; Noguchi et al., 1989; Uhlig \& Wendel, 1990).

However, since the introduction of GSH monoester, it was 


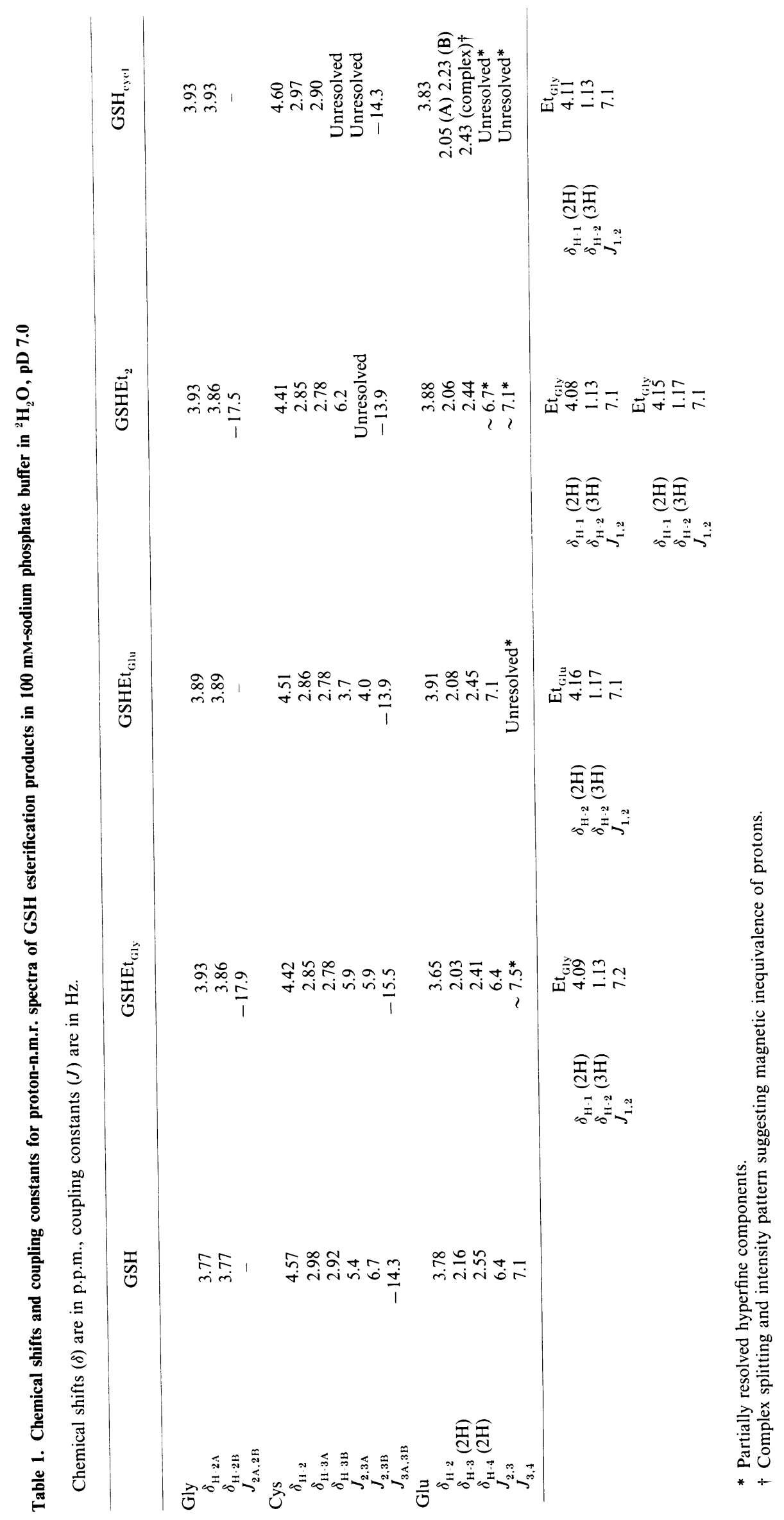

Vol. 275 

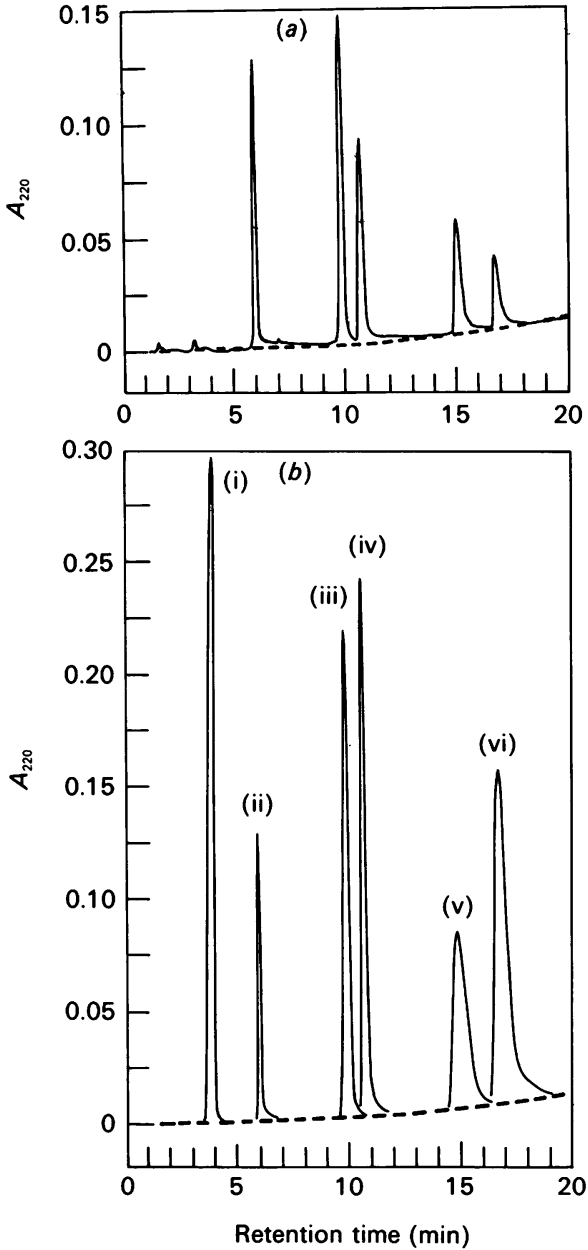

Fig. 2. Analytical reverse-phase h.p.l.c. of GSH esterification products

(a) Sample: $50 \mu \mathrm{g}$ of a $30 \mathrm{~min}$ esterification product mixture in mobile phase, $\mathrm{pH} 2.83$. (b) Overlay of chromatograms of pure fractions as described for Fig. 1(b). Assignments: (i) GSH; (ii) $S$-methylglutathione (internal standard); (iii) $\mathrm{GSHEt}_{\text {Gly }}$; (iv) GSHEt $_{\text {Glu }}$; (v) GSHEt $_{2}$; (vi) $\mathrm{GSH}_{\text {cycl }}$. The ODS column size was $8 \mathrm{~mm}$ internal diam. $\times 10 \mathrm{~cm}$, the flow rate was $2 \mathrm{ml} / \mathrm{min}$, the mobile phase was $10 \mathrm{~mm}$-sodium phosphate buffer, $\mathrm{pH} 2.83$, and the gradient was $0-50 \%(\mathrm{v} / \mathrm{v})$ methanol during 0-20 min.

Table 2. T.l.c. of GSH esterification products on silica gel 60

Mobile phase compositions were as follows: A, propan-1-ol/acetic acid/water (10:1:5, by vol.); B, propan-1-ol/acetic acid/water (10:5:1, by vol.). Detection was with $0.2 \%$ ninhydrin in ethanol.

\begin{tabular}{llll}
\hline & & \multicolumn{2}{c}{$R_{F}$} \\
\cline { 3 - 4 } Compound & Mobile phase ... & $\mathrm{A}$ & $\mathrm{B}$ \\
\hline & & 0.38 & 0.30 \\
GSH & & 0.71 & 0.60 \\
GSHEt $_{\text {Gly }}$ & & 0.71 & 0.60 \\
GSHEt $_{\text {Glu }}$ & & 0.82 & 0.87 \\
GSHEt $_{2}$ & & $0.73^{*}$ & $0.90^{*}$
\end{tabular}

* The cyclization product was not resolved from GSHEt (A) or $\mathrm{GSHET}_{2}$ (B).

possible that two monoesters, GSHEt $\mathrm{Gly}_{\text {and }}$ anSEt $\mathrm{Glu}_{\mathrm{G}}$, would be formed in acid-catalysed esterification reations. Reversephase h.p.l.c. was found to resolve two monoesters that gave proton-n.m.r. spectra consistent with GSH esterified on the glycine residue or on the $\gamma$-glutamic acid residue.

The proton-n.m.r. spectrum of GSH in neutral aqueous solution is indicative of a glycine residue with free rotation around the methylene group and a transient interaction between the carboxylate $-\mathrm{CO}_{2}^{-}$group and/or the ammonium $-\mathrm{NH}_{3}^{+}$ group of the glutamic acid residue with the $\gamma$-glutamyl-cysteinyl peptide bond (York et al., 1987; Laurence \& Thomson, 1980). Esterification of the glycine residue produced magnetic inequivalence of the $\alpha-\mathrm{CH}_{2}$ protons with a geminal coupling constant $J \approx-17.5--17.9 \mathrm{~Hz}$. Esterification on the glutamic acid residue increased the chemical shift of the $\alpha-\mathrm{CH}$ resonance, consistent with an un-ionized carboxylate group (Rabenstein \& Keire, 1989). However, the chemical shift of the $\alpha-\mathrm{CH}_{2}$ protons of the glycine residue was greater than that in GSH for $\mathrm{GSHEt}_{\mathrm{Gly}}, \mathrm{GSHEt}_{\mathrm{Glu}}, \mathrm{GSHEt}_{2}$ and $\mathrm{GSHEt}_{\mathrm{cycl}}$; the value for GSHEt $_{\text {Glu }}$ was expected to be less than that for GSH, by similarity to the change during protonation of the $\gamma$-carboxylate group in GSH (Rabenstein \& Keire, 1989). This unexpected trend may be due to a change in the intramolecular associations imposed by glycine esterification.

Acid-catalysed cyclization is expected under the strong acid conditions used (Bodanszky, 1988). The suggested intramolecular interactions in GSH (Laurence \& Thomson, 1980; York et al., 1987; Rabenstein \& Keire, 1989) are consistent with the reactive groups involved in the proposed cyclization, the carboxylate group of the glutamic acid residue and the $-\mathrm{NH}-$ group of the $\gamma$-glutamyl-cysteinyl peptide bond, transiently being in close proximity.

My preliminary investigations into the kinetics of GSH esterification suggest that, even when the rate of esterification of GSH is decreased by using less severe catalytic conditions (aqueous $90 \%$ ethanol containing $1 \mathrm{M}-\mathrm{HCl}$ ), there is still formation of detectable amounts of GSHEt $\mathrm{Glu}_{\mathrm{u}}, \mathrm{GSHEt}_{2}$ and $\mathrm{GSH}_{\mathrm{cycl}}$.

The methods described can be used to prepare GSH esters and related derivatives for biological evaluation. The relative effectiveness of each of these compounds on supplementing cellular GSH concentrations can now be determined.

I thank members of my research group for help and discussion. This is a contribution from Glyoxalase Research Group at the University of Essex.

\section{REFERENCES}

Anderson, M. E., Powrie, F., Puri, R. N. \& Meister, A. (1985) Arch. Biochem. Biophys. 239, 538-548

Astor, M. B., Anderson, M. E. \& Meister, A. (1988) Pharmacol. Ther. $39,115-121$

Bodanszky, M. (1988) Peptide Chemistry, p. 108, Springer-Verlag, Berlin Bottje, W., Glahn, R., Nejad, H., Beers, K. \& Holmes, K. (1989) Med. Sci. Res. 17, 991-993

Hagen, T. M., Brown, L. A. \& Jones, D. P. (1986) Biochem. Pharmacol. 35, 4537-4542

Lash, L. H. \& Jones, D. P. (1984) J. Biol. Chem. 259, 14508-14514

Lash, L. H., Hagen, T. M. \& Jones, D. P. (1986) Proc. Natl. Acad. Sci. U.S.A. 83, $4641-4645$

Laurence, P. R. \& Thomson, C. (1980) Theor. Chim. Acta 57, 25-41

Meister, A. (1988) J. Biol. Chem. 263, 17205-17208

Noguchi, K., Higuchi, S. \& Matsui, M. (1989) Res. Commun. Chem. Pathol. Pharmacol. 64, 165-168

Puri, R. N. \& Meister, A. (1983) Proc. Natl. Acad. Sci. U.S.A. 80, $5258-5260$

Rabenstein, D. L. \& Keire, D. A. (1989) in Coenzymes and Cofactors, vol. 3: Glutathione, part A (Dolphin, D., Poulson, R. \& Avramovic, O., eds.), pp. 67-101, Wiley-Interscience, New York

Richman, P. \& Meister, A. (1983) J. Biol. Chem. 250, 1422-1426

Singh, A., Lee, K. J., Lee, C. Y., Goldfarb, R. D. \& Tsan, M.-F. (1989) Circulation 80, 1795-1804 
Teicher, B. A., Crawford, J. M., Holden, S. A., Tsan, M.-F., White, J. E. \& Rosano, C. L. (1988) J. Appl. Physiol. 66, 1029-1034

Tsan, M.-F., White, J. E. \& Rosano, C. L. (1989). J. Appl. Physiol. 66, 1029-1034

Uhlig, S. \& Wendel, A. (1990) Biochem. Pharmacol. 39, 1877-1881

Received 10 January 1991; accepted 6 February 1991
Vos, O. \& Roos-Verhey, W. S. D. (1988) Int. J. Radiat. Biol. 53, 273-281 Wellner, V. P., Anderson, M. E., Puri, R. N., Jensen, G. L. \& Meister, A. (1984) Proc. Natl. Acad. Sci. U. S. A. 81, 4732-4735

York, M. J., Beilharz, G. R. \& Kuchel, P. W. (1987) Int. J. Pept. Protein Res. 29, 638-646 